\title{
Bioequivalence Study of Two 50 mg Desvenlafaxine Extended Release Formulations: A Randomized, Single-Dose, Open-Label, Two Periods, Crossover Study
}

\author{
Vargas $\mathrm{M}^{1 *}$, Villarraga $\mathrm{E}^{2}$ and Vargas $\mathrm{Jba}^{3}$ \\ ${ }^{1}$ Odontologist, Pharmacologist, Scientific Director Pharmacology Unit La Sabana University, Bogotá - Colombia \\ ${ }^{2}$ Physician, Pharmacologist, Clinical phase Medical Coordinator, Bogotá - Colombia \\ ${ }^{3}$ Pharmaceutical Chemist, Toxicologist, analytical method Responsible, Bogotá - Colombia
}

\begin{abstract}
This is a pharmacokinetic study of two formulations containing Desvenlafaxine succinate $50 \mathrm{mg}$ extended release. Its objective was to compare the bioavailability between the Test product (Desvenlafaxine ER produced by Tecnoquímicas S.A., Colombia laboratory) and the Reference product (Pristiq $\mathrm{XR}^{\circledR}$ produced by Wyeth laboratory) and to be able to determine the Bioequivalence between the both of them. For this, an open label, two periods, two previously randomized sequences, crossover, single postprandial $100 \mathrm{mg}$ dose study with an 8 days washout period between each period in 24 healthy volunteers was performed, including the collection of 13 plasma samples within 0 and 48 hours from all volunteers who participated in the clinical phase. The analytical method used was High Performance Liquid Chromatography (HPLC) with UV detector. The obtained mean peak concentration $\left(\mathrm{C}_{\max }\right)$ for the Test and Reference products were $215.8 \mathrm{ng} / \mathrm{mL}$ and $196.9 \mathrm{ng} / \mathrm{mL}$ and for the area under the curve up to 48 hours $\left(A \cup C_{0 . t}\right) 3849,6 \mathrm{ng} . \mathrm{h} / \mathrm{mL}$ and $3605,4 \mathrm{ng} \cdot \mathrm{h} / \mathrm{mL}$ respectively. The $90 \%$ confidence interval for the $\mathrm{C}_{\max }$ parameter is within the range of $103,58-113,63$ and for the $A_{U C}$ parameter, the $90 \%$ confidence interval is within $97,96-111,39$. Based on the FDA, EMA and WHO bioequivalence investigation guidelines, the $\mathrm{Cl}$ is within the allowed ranges for bioequivalence and interchangeability declaration of the Tecnoquímicas S.A. product with the Reference product.
\end{abstract}

Keywords: Bioequivalence; Desvenlafaxine; Antidepressant; Pharmacokinetics

\section{Introduction}

Desvenlafaxine is the O-desmethyl active metabolite of venlafaxine, which presents a dual mechanism of action inhibiting the serotonin and adrenaline recapture in the synaptic cleft through serotonin (SERT) and noradrenaline transporters (NERT) blocking in the presynaptic membrane. It was approved in 2008 by the FDA for the Major Depressive Disorder (MDD) treatment given its short-term safety, tolerability and demonstrated efficacy in placebo-controlled trials [1-3]. In its succinate salt form, an extended active ingredient release is produced, allowing the administration of one tablet every 24 hours since it has a plasma concentration peak at 6 to 8 hours in fasting conditions ( 8 to 10 hours if taken postprandial) and an elimination half-life between 9 to 15 hours [4,5]. It has linear kinetics in the 100 to $600 \mathrm{mg}$ /day range, although its antidepressant efficacy has been demonstrated with $50 \mathrm{mg} /$ day doses. Its oral Bioavailability is $80 \%$ and it is not modified by low fat meals [4,5]. It is mainly metabolized by glucuronidation through UDP-glucuronyltransferase and to a lesser extent through the cytochrome CYP3A4 oxidative pathway. This pharmacokinetic characteristic decreases its interindividual variability given the slightest polymorphism observed in this enzyme, opposite to the metabolism description of venlafaxine, which is mainly metabolized by the CYP2D6 cytochrome pathway, an enzyme likely to present such polymorphisms.

The major depressive disorder is a mental disease with a high prevalence in adult population (close to $7 \%$ ) and a prediction of becoming the main world disability cause by 2030 [5,6]. This pathology has an adverse impact in patients with related diseases, such as cardiovascular disease and chronic pain handling, being the pharmacological treatment the main support for its treatment.

The objective of this study was to establish the Bioequivalence of two formulations containing Desvenlafaxine succinate $50 \mathrm{mg}$ tablets by comparing its Bioavailability after a single dose between the Test product (produced by Tecnoquímicas S.A., Colombia) and the Reference product (Pristiq $\mathrm{XR}^{\circledR}$ produced by Wyeth).

\section{Materials and Methods}

\section{Study formulations}

The Test formulation was Desvenlafaxine $50 \mathrm{mg}$ extended release tablets produced by Tecnoquímicas S.A, Cali-Colombia (Batch EX3D09) and the Reference product was Pristiq ${ }^{\mathbb{B}}$-Desvenlafaxine $50 \mathrm{mg}$ extended release tablets produced by Wyeth (Batch 82386).

Physical-chemical properties, active ingredient assessment, dose uniformity and dissolution profile were evaluated for both the Test and Reference products in order to determine the Pharmaceutical Equivalence of these before carrying out the in vivo study.

\section{Subjects}

Twenty four healthy non-smoking female and male subjects, aged between 18 and 42 years old with a Body Mass Index (BMI) of

*Corresponding author: Vargas M, Scientific Director, Pharmacology Unit La Sabana University, Bogotá - Colombia, Tel: 555-23-34 Ext. 8106; E-mail mjcruz@tecnoquimicas.com

Received May 14, 2014; Accepted June 29, 2014; Published July 05, 2014

Citation: Vargas M, Villarraga E, Vargas Jba (2014) Bioequivalence Study of Two $50 \mathrm{mg}$ Desvenlafaxine Extended Release Formulations: A Randomized, SingleDose, Open-Label, Two Periods, Crossover Study. J Bioequiv Availab 6: 115-118. doi:10.4172/jbb.1000189

Copyright: ( 2014 Vargas M, et al. This is an open-access article distributed under the terms of the Creative Commons Attribution License, which permits unrestricted use, distribution, and reproduction in any medium, provided the original author and source are credited. 
Citation: Vargas M, Villarraga E, Vargas Jba (2014) Bioequivalence Study of Two $50 \mathrm{mg}$ Desvenlafaxine Extended Release Formulations: A Randomized, Single-Dose, Open-Label, Two Periods, Crossover Study. J Bioequiv Availab 6: 115-118. doi:10.4172/jbb.1000189

$19-25 \mathrm{~kg} / \mathrm{m}^{2}$ participated. All volunteers were assessed with a medical examination and laboratory tests before the clinical phase initiation to confirm their health condition. Alcoholism history, preexistent diseases compromising liver or kidney function, blood dyscrasia or proteinuria were considered as exclusion factors.

\section{Medical examinations and clinical laboratory tests}

Performed clinical laboratory tests included $\mathrm{CBC}$, total and direct bilirubin, creatinine, glycaemia, total protein, complete urinalysis, HIV Elisa test, antibodies against hepatitis B and C, electrocardiogram and blood pregnancy test for women.

\section{Informed consent process}

The protocol and the informed consent were authorized by the La Sabana University Clinical Research Ethics Committee (CREC) which is ruled by the legal and ethical guidelines of the resolutions 008430 of 1993 and 002378 of 2008 of the Ministry of Social Protection (Colombia), World Conference on Harmonization for Good Clinical Practice of Institutions Conducting Investigation in Human Subjects and by the World Medical Assembly principles published in the Declaration of Helsinki, last review in 2008 [7-9].

A chat addressed to the volunteers was performed in order to explain the study in detail emphasizing in the type of medication to be used, planned dose, potential drug adverse reactions, blood volume to be collected at each study phase, the material to be used to collect the samples, the staff in charge of collecting them, diet restrictions to comply with, expected benefits for the community with the results and all the information they requested to freely decide their participation in the study. Subsequently, every one of them signed an informed consent form.

\section{Study design}

A randomized, open-label, two periods, two sequences, crossover design was used with an 8 days washout period between each period. Both products (Test and Reference) were administered 30 minutes after breakfast. The washout period was higher than 5 active ingredient half-lives. Three days before each period initiation, volunteers must refrain from medications, alcohol and any food or drink containing methylxantines. These restrictions prevailed during the whole sample collecting period. All volunteers were randomized to be allocated to the treatment sequence.

\section{Drug administration}

All volunteers received breakfast according to a regular diet in Colombia. Thirty minutes later, 2 tablets containing $50 \mathrm{mg}$ of medication each (a total of $100 \mathrm{mg}$ Desvenlafaxine succinate) were administered with $200 \mathrm{~mL}$ of water. During the entire experimental day, food intake completed 2600 calories divided into $85 \mathrm{~g}$ of protein, $78 \mathrm{~g}$ of fat and $390 \mathrm{~g}$ of carbohydrates. The plasma sample collecting team was confirmed by a physician and two licensed nurses. By means of a vacutainer ${ }^{\circledR}$, a blood sample was collected by venipuncture in the superior limb immediately prior to administering the medication. Such sample was called zero time point sample. All volunteers received the Test product and the Reference product in each sequence. Thirteen blood venous samples were collected according to the following time points: $0 ; 2 ; 3 ; 4 ; 5 ; 6 ; 7 ; 8 ; 10 ; 12 ; 24 ; 36$ and 48 hours. Samples were labeled for identification and centrifuged at $3000 \mathrm{rpm}$ for 30 minutes. Plasma was transferred to a previously labeled tube and frozen at $-20^{\circ} \mathrm{C}$ for later analysis.

\section{Analytical methodology}

Desvenlafaxine was quantified in plasma using a validated method. HPLC-UV method consisted of Desvenlafaxine extraction from 1,0 $\mathrm{mL}$ test plasma sample in a sedimentation centrifuge screw tap tube containing $60 \mu \mathrm{L}$ of concentrated ammonium hydroxide. It underwent 20 seconds vortex stirring. $4 \mathrm{~mL}$ diethyl ether was added to this mixture and it underwent extra 60 seconds vortex stirring. Subsequently, it was centrifuged at 5000 r.p.m for 5 minutes. The organic layer was extracted in a glass tube and evaporated to dryness at $50^{\circ} \mathrm{C}$ under a gaseous nitrogen stream. Finally, the residue was reconstituted with 1,0 $\mathrm{mL}$ diluent solution and underwent 30 seconds vortex stirring. $100 \mu \mathrm{L}$ were filtered and injected to the chromatographic system for RP-HPLC and UV detection analysis.

\section{Pharmacokinetic analysis}

The pharmacokinetic analysis was performed using WinNonlin 5.3 (Pharsight Corporation, Cary USA) software, by means of a noncompartmental analysis. Peak concentration $\left(\mathrm{C}_{\max }\right)$ and the time to peak concentration $\left(\mathrm{T}_{\max }\right)$ were obtained directly from the results of plasma concentrations, just as recommended by the FDA and the European Medicines Agency (EMA) for drug assessment [10-12].

Area under the curve, $\mathrm{AUC}_{0 \mathrm{t}}$, between zero time point and the last time point with detectable concentrations was calculated through the trapezoidal rule, guaranteeing the calculation of at least $80 \%$ of the AUC with the last sample. The $\mathrm{AUC}_{\mathrm{t}-\infty}$ was calculated as the $\mathrm{C} / \mathrm{Ke}$ coefficient, being $\mathrm{C}$ the last detectable concentration and $\mathrm{K}_{e}$ the elimination constant, estimated as the slope obtained by linear regression from the points corresponding to the drug elimination phase through a linear regression of natural logarithm of concentrations [13]. Bioavailabilityadjusted elimination constant $\left(\mathrm{K}_{\mathrm{e}}\right)$, half-life $\left(\mathrm{t}^{1 / 2}\right)$, clearance $(\mathrm{Cl})$ and half mean residence time (MRT) were calculated after performing the non-compartmental analysis. The results of pharmacokinetic variables are summarized in Tables 3 and 4 with $\mathrm{AUC}_{0-\infty}, \mathrm{AUC}_{0-\mathrm{t}}, \mathrm{C}_{\max }$ and $\mathrm{T}_{\max }$ values and the elimination time $t_{1 / 2}$ of each one of the volunteers for each studied formulation.

\section{Statistical analysis}

An analysis of variance (ANOVA) was used to determine possible effects for each variation factor by sequence, period or subject. For this purpose, an F-test with a statistical significance level of $5 \%(\alpha=0,05)$ was used. The statistical comparison of transformed pharmacokinetic parameters of both formulations was performed using the statistical software WinNonlin version 5.3. Pharmacokinetic parameters $\mathrm{C}_{\max }$ and $\mathrm{AUC}_{0-\mathrm{t}}$ were logarithmically transformed to conclude Bioequivalence if they met the $90 \%$ confidence interval within the $80-125 \%$ accepted limit range.

\section{Adverse events report}

Adverse events were recorded according to INVIMA guidelines Provision No. 1067/08, which defines them as serious or not serious and then, according to its definition, as likely, potential or not related relationship with the study medication. Since the sample size is not large, cases are informed as received from the investigation unit only and without any statistical estimation.

\section{Results}

Analytical results of active ingredient content, dose uniformity and dissolution test met the required specifications set by the Pharmaceutical Equivalence statement. Additionally, the comparative 
Citation: Vargas M, Villarraga E, Vargas Jba (2014) Bioequivalence Study of Two $50 \mathrm{mg}$ Desvenlafaxine Extended Release Formulations: A Randomized, Single-Dose, Open-Label, Two Periods, Crossover Study. J Bioequiv Availab 6: 115-118. doi:10.4172/jbb.1000189

dissolution profiles study showed a difference factor $\left(f_{1}\right)$ of 4 and a similitude factor $\left(\mathrm{f}_{2}\right)$ of 77 Table 1 .

The analytical method allowed the selective determination of Desnenlafaxine within the 5.0 to $270.0 \mathrm{ng} / \mathrm{ml}$ range of only $1 \mathrm{~mL}$ plasma. Method selectivity was proved through the analysis of six blank samples in which no interferences were detected between the analyte and the matrix endogenous compounds. Three Desvenlafaxine calibration curves were performed in human serum which showed to be linear within the $5 \mathrm{mg} / \mathrm{mL}$ to $300 \mathrm{ng} / \mathrm{mL}$ concentration range with linear correlation coefficients of $0.9977,0.9986$ and 0.9980 ; three Desvenlafaxine calibration curves were also performed in diluent solution, which showed to be linear in the same concentration range, with linear correlation coefficients of $0.9999 ; 0.9999$ and 0.9998 . Detection limit for the study was $1.7 \mathrm{ng} / \mathrm{mL}$ and quantitation limit was $5.0 \mathrm{ng} / \mathrm{ml}$, which allows to perform a calibration curve in a wider concentration range. Precision expressed in terms of intratest coefficient of variation was $14.8 \%$ for $15 \mathrm{mg} / \mathrm{mL}, 1.2 \%$ for $150 \mathrm{mg} / \mathrm{mL}$ and $3.0 \%$ for $270 \mathrm{ng} / \mathrm{mL}$ and interday coefficient of variation was $2.3 \%$ for $15 \mathrm{mg} / \mathrm{mL}, 5 \%$ for $150 \mathrm{mg} / \mathrm{mL}$ and $4.1 \mathrm{mg} / \mathrm{mL}$ for $270 \mathrm{ng} / \mathrm{mL}$. All these values are below $15 \%$ for low, medium and high concentrations. The method is accurate as well, since the relative intratest and intertest error values were also below $15 \%$ with $-14.1 \%, 3.4 \%$ and $5.0 \%$ for $15 \mathrm{ng} /$ $\mathrm{mL}, 150 \mathrm{ng} / \mathrm{mL}$ and $280 \mathrm{ng} / \mathrm{mL}$, respectively and $-5.2 \%, 6.4 \%$ and $9.1 \%$ for the same concentrations. Regarding the Desvenlafaxine recovery percent in human serum, percentages of $81.4 \%$ for $15 \mathrm{ng} / \mathrm{mL}, 84.7 \%$ for $150 \mathrm{ng} / \mathrm{mL}$ and $81.8 \%$ for $270 \mathrm{ng} / \mathrm{ml}$ were obtained with coefficients of variation of $5.5 \%, 6.0 \%$ and $8.4 \%$ respectively. Samples showed stability when stored at room temperature and refrigeration for 24 hours only, since after two storage days, evaluation showed evidence of degradation in $15 \mathrm{ng} / \mathrm{mL}$ concentration samples. Samples are stable in the freezingthaw process for at least 3 cycles when stored at $-20^{\circ} \mathrm{C}$. It was therefore concluded that the quantitation method for Desvenlafaxine is selective, precise, accurate and shows good stability in human serum under analytical and instrumental laboratory conditions.

The study involved the participation of 24 healthy Colombian volunteers of both genders ( $50 \%$ women and $50 \%$ men) who completed both periods and were included in the pharmacokinetic and statistical analysis. Both treatments were well tolerated with the occurrence of adverse events considered as mild. The most commonly reported $\mathrm{AE}$ were nausea and pyrosis in $25 \%$ of the volunteers for both Test and Reference products (Table 2). Table 3 shows pharmacokinetic parameters obtained from all volunteers (mean \pm SD) and Figure 1 shows comparative Bioavailability curves. The statistical analyses performed to determine Bioequivalence between the Test product Styma ${ }^{\circledR}$ produced by Tecnoquímicas S.A. and Pristiq ${ }^{\circledR}$ produced by Wyeth are shown in Table 4.

\section{Discussion}

The reduction in costs of mental disorders treatment using multisource products showing the same quality and safety is a desired aim by governments interested in reducing the original drugs high costs. For this purpose, Bioequivalence studies assure the same pharmacokinetics for both generic and innovative products with no need of repeating clinical trials in new patients $[14,15]$.

A rapid active ingredient release and a sudden increase of plasma concentration of Desvenlafaxine was discarded when performing the in vivo test with food presence according to WHO recommendations for products with a modified release system [16]. These findings are consistent with a study for assessment of Desvenlafaxine succinate pharmacokinetic changes when administered with or without food and that did not report significant changes in the molecule Bioavailability when interacting with food in the intestine [4]. The obtained values for $\mathrm{C}_{\max }$ and $\mathrm{AUC}_{0-\mathrm{t}}$ either for the Test and Reference products are similar to those obtained in other studies [17].

This two periods, two sequences, crossover, single-dose design with healthy volunteers minimized the variability that is not due to formulation effects. The analytical method used was selective, precise,

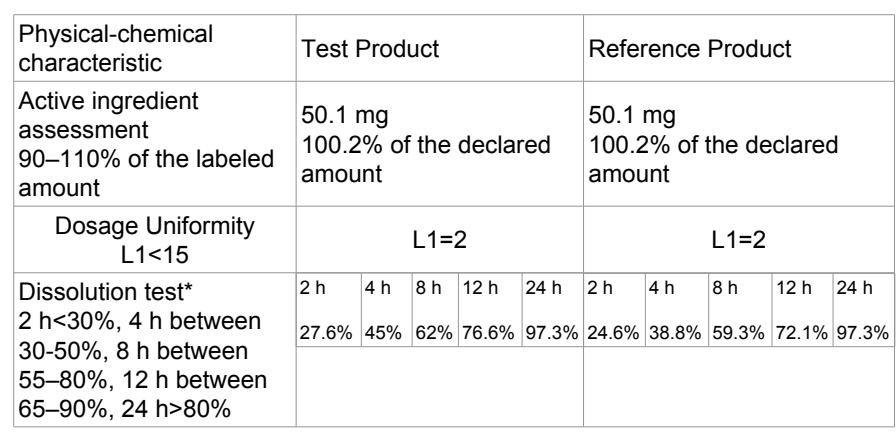

Dissolution time mean for 12 tablets

Table 1: Test and Reference product physical-chemical tests results.

\begin{tabular}{|c|c|}
\hline Demographic Variable & Obtained mean $(\mathbf{n}=\mathbf{2 4})$ \\
\hline Gender & $\begin{array}{c}12 \text { women } \\
12 \text { men }\end{array}$ \\
\hline Age (years) & $29 \pm 7.5$ \\
\hline Height $(\mathrm{cm})$ & $167 \pm 8.3$ \\
\hline Weight $(\mathrm{kg})$ & $63 \pm 8.5$ \\
\hline BMl $\left(\mathrm{kg} / \mathrm{m}^{2}\right)$ & $22 \pm 1.7$ \\
\hline
\end{tabular}

Table 2: Demographics of volunteers included in the pharmacokinetic and statistical analysis.

\begin{tabular}{|c|c|c|}
\hline Parameter (unit) & Test Product & Reference Product \\
\hline $\mathbf{C}_{\max }$ (ng/mL) & $215 \pm 69.9$ & $196.9 \pm 58.2$ \\
\hline AUC $_{0-\mathrm{t}}$ (ng.h/mL) & $3849.6 \pm 1664.3$ & $3605.4 \pm 1412.1$ \\
\hline AUC $_{0-\infty}$ (ng.h/mL) & $4233.7 \pm 2076.8$ & $3905.8 \pm 1490.9$ \\
\hline $\mathbf{T}_{\max }$ (h) & $6.3 \pm 1.4$ & $6.4 \pm 1.7$ \\
\hline $\mathbf{K}_{\mathbf{e}}$ (1/h) & $0.079 \pm \mathrm{SD}$ & $0.068 \pm \mathrm{SD}$ \\
\hline $\mathbf{T}_{1 / 2}$ (h) & $10.5 \pm \mathrm{SD}$ & $11.5 \pm \mathrm{SD}$ \\
\hline
\end{tabular}

Table 3: Pharmacokinetic parameters of desvenlafaxine succinate for Test product $\left(\right.$ Styma $^{\circledR}$ ) and Reference product (Pristiq ${ }^{\circledR}$ ) followed by a $100 \mathrm{mg}$ single oral postprandial dose. Mean and Standard Deviation are presented.

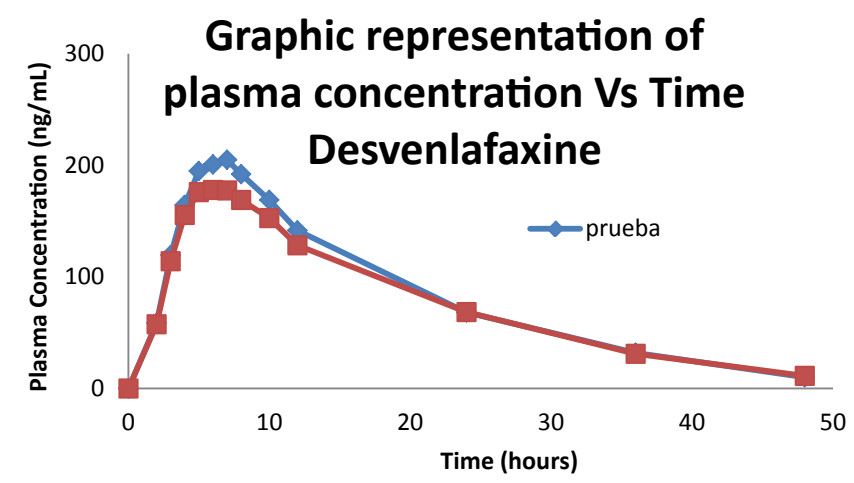

Figure 1: Bioavailability curve (Concentration vs. Time) obtained after a $100 \mathrm{mg}$ postprandial dose of Desvenlafaxine succinate of the Test product $\left(\right.$ Styma $\left.^{\circledR}\right)$ and the Reference product (Pristiq ${ }^{\circledR}$ from Wyeth). 
Citation: Vargas M, Villarraga E, Vargas Jba (2014) Bioequivalence Study of Two $50 \mathrm{mg}$ Desvenlafaxine Extended Release Formulations: A Randomized, Single-Dose, Open-Label, Two Periods, Crossover Study. J Bioequiv Availab 6: 115-118. doi:10.4172/jbb.1000189

\begin{tabular}{|c|c|c|cc|}
\cline { 2 - 5 } \multicolumn{1}{c|}{} & Units & Ratio\% T/R & Standard Cl 90\% (Test/Reference) \\
\hline In $\mathbf{C}_{\max }$ & $\mathrm{ng} / \mathrm{mL}$ & 108.49 & 103.58 & 113.63 \\
\hline In AUC & $\mathrm{hr}{ }^{*} \mathrm{ng} / \mathrm{mL}$ & 104.46 & 97.96 & 111.39 \\
\hline In AUC & $\mathrm{hr}{ }_{0-\infty} \mathrm{ng} / \mathrm{mL}$ & 104.57 & 98.32 & 111.21 \\
\hline In $\mathbf{T}_{\max }$ & $\mathrm{hr}$ & 98.6 & 89.86 & 108.2 \\
\hline
\end{tabular}

Table 4: $90 \% \mathrm{Cl}$ of logarithmically transformed pharmacokinetic parameters of two formulations containing Desvenlafaxine succinate (Test and Reference products) after its administration to healthy volunteers.

accurate and robust. All volunteers completed the study and only mild adverse events occurred when administering both formulations. The washout period was higher than the recommended 5 elimination halflives and guaranteed the absence of carryover effect between periods. The Pharmaceutical Equivalence Statement and the similitude between dissolution profiles while estimating a non-difference factor $\left(f_{1}\right)<15$ and a similitude factor $\left(\mathrm{f}_{2}\right)>50$ allowed to rate the in vitro quality attributes for both formulations. It was shown that mean values for AUC $_{0-t}$ and $\mathrm{C}_{\max }$ parameters were not significantly different between products and that the $90 \%$ confidence intervals for $\mathrm{C}_{\max }$ and $\mathrm{AUC}_{0-\mathrm{t}}$ for Test/Reference proportions remained within the ranges established by the regulatory entities for the Bioequivalence statement. The study sampling time was 48 hours, obtaining an $\mathrm{AUC}_{0-\mathrm{t}}$ greater than $80 \%$, as suggested by the FDA published guideline [11].

Nichols et al [4] reported a Desvenlafaxine $\mathrm{T}_{\max }$ of approximately 6 hours in fasting conditions and approximately 2 to 4 additional hours when administered with food without affecting the apparent elimination half-life of oral dose except for the peak mean plasma concentration reached in postprandial conditions with a high fat content [4]. The lowest increase of peak plasma concentration in high fat content conditions was not clinically relevant [4]. In our study, there was no effect in the mean $\mathrm{T}_{\max }$ extension for both products following a regular Colombian diet. However, being an extended release pharmaceutic form, it is important to note that $\mathrm{T}_{\max }$ for both products are similar, and that the Test drug elimination profile is the same of the Reference product profile. The extended release characteristics are then preserved, allowing a single daily dose administration, favoring a higher therapeutic adherence.

\section{Conclusions}

The Desvenlafaxine ER formulation Styma ${ }^{\circledR}$ manufactured by Tecnoquímicas S.A. (Test product) and Pristiq ${ }^{\circledR}$ manufactured by Wyeth (Reference product) have the pharmacokinetic parameters leading to the Bioequivalence statement between both formulations.

\section{Acknowledgement}

The test product is manufactured by Tecnoquímicas S.A. in Jamundí, Colombia under the trademarks Styma ${ }^{\circledR}$ and Desvenlafaxina $\mathrm{MK}^{\circledR}$ in Colombia Desvenlafaxina $\mathrm{MK}^{\circledR}$ in Ecuador and Desvenlafaxteg $\mathrm{TG}^{\circledR}$ in Central America.

\section{References}

1. Seo HJ, Sohi MS, Patkar AA, Masand PS, Pae CU (2010) Desvenlafaxine succinate: a newer antidepressant for the treatment of depression and somatic symptoms. Postgrad Med 122: 125-138.

2. Pristiq (2011) PA: Wyeth Pharmaceuticals Inc, a subsidiary of Pfizer Inc Philadelphia

3. Pfizer Pipeline as of (2011). Accessed 3-3-2011

4. Nichols AI, Richards LS, Behrle J, Posener JA, Paul J (2012) Effect of Food on the Pharmacokinetics of Desvenlafaxine in Healthy Subjects. J Bioequiv Availab 4: 24-29.

5. Perry R, Cassagnol M (2009) Desvenlafaxine: A New Serotonin-Norepinephrine reuptake Inhibitor for the Treatment of Adults with Major Depressive Disorder. Clin Ther 31: 1374-1404.

6. http://www.nimh.nih.gov/statistics/1mdd_adult.shtml

7. Koen Van der Kooy, Hein van Hout, Harm Marwijk, Haan Marten, Coen Stehouwer, Aartja, et al. (2007) Depression and the risk for cardiovascular diseases: systematic review and meta-analysis. Int J Geriatr Psychiatry 22 613-626.

8. Nichols A, Behrle J, Parks V, Richards L, McGrory S, et al. (2013) Pharmacokinetics, Pharmacodynamics and Safety of Desvenlafaxine a Serotonin-Norepinephrine Reuptake Inhibitor. J. Bioequiv Availab 5: 22-30.

9. World Medical Association Declaration of Helsinki (2008) Ethical principles for the medical research involving human subjects adopted by the: 59th General Assembly Seoul. Korea.

10. Food and Drugs Administration (2009) Guidance for industry Statistical Approaches to Establishing Bioequivalence.

11. U.S. Department of Health and Human Services (2010) Food and Drug Administration, Guidance for Industry. Bioavailability and Bioequivalence Studies for Orally Administered Drug Products - General Considerations.

12. Committee for Proprietary Medicinal Products (2011) Note for guidance on the investigation of Bioavailability and Bioequivalence.The European Agency for the Evaluation of Medicinal Products.

13. Wagner JG (1971) Biopharmaceutics and Relevant pharmacokinetics. (First edition) Drug Intelligence Publications, Hamilton.

14. Perry $R$ (2010) Perspectives on the bioequivalence and therapeutic equivalence of generic formulations: An overview of the landscape.Clin Ther 32: 1796-1797.

15. Thota S, Tippabhotla S, Khan S, Nakkawar M (2013) Two-way crossover bioequivalence study of rosuvastatin tablets $5 \mathrm{mg}$ in healthy, adult, asian-indian male volunteers under fasting condition. Int J Pharm Sci 5: 289-293.

16. WHO (2006) Who expert committee on specifications for pharmaceutical preparations.

17. Baird-Bellaire S, Behrle JA, Parker VD, Patat A, Paul J, et al.(2013) An OpenLabel, Single-Dose, Parallel-Group Study of the Effects of Chronic Hepatic Impairment on the Safety and Pharmacokinetics of Desvenlafaxine. Clinical Therapeuticas 35: 782-794. 